\title{
Detection of Vancomycin-Resistant Enterococci and Related Genes Using VITEK 2 System and Multiplex Real-time PCR Assay
}

\author{
Min-Kyung Jeong ${ }^{1}$, Young-Bin $\mathrm{Yu}^{2}$, Sang-Ha Kim ${ }^{3}$, Sunghyun Kim ${ }^{4}$, Young-Kwon Kim ${ }^{2}$ \\ ${ }^{1}$ Department of Laboratory Medicine, Chonnam National University Hospital, Gwangju, Korea \\ ${ }^{2}$ Department of Biomedical Laboratory Science, College of Medical Sciences, Konyang University, Daejeon, Korea \\ ${ }^{3}$ Department of Laboratory Medicine, Konyang University Hospital, Daejeon, Korea \\ ${ }^{4}$ Department of Clinical Laboratory Science, College of Health Sciences, Catholic University of Pusan, Busan, Korea
}

\section{VITEK 2 시스템과 Multiplex Real-time PCR을 이용한 반코마이신 내성 장알균(VRE)과 내성관련 유전자 검출}

정민경 ${ }^{1}$, 유영빈 $^{2}$, 김상하 ${ }^{3}$, 김성현 ${ }^{4}$, 김영권 ${ }^{2}$

${ }^{1}$ 전남대학교병원 진단검사의학과, ${ }^{2}$ 건양대학교 의과학대학 임상병리학과, ${ }^{3}$ 건양대학교병원 진단검사의학과, ${ }^{4}$ 부산가톨릭대학교 보건과학대학 임상병리학과

\begin{abstract}
In this study, using the VITEK 2 system, 74 samples (22.6\%) out of 327 specimens were identified by the growth of Enterococcosel media (EV6 agar) supplemented with $6 \mu \mathrm{g} / \mathrm{mL}$ of vancomycin. Enterococcus faecium was identified as 55 strains (74.3\%), Enterococcus casseliflavus as 2 strains (2.7\%), Enterococcus aviumas 1 strain (1.4\%), and Enterococcus gallinarum as 16 strains (21.6\%). Among the 55 phenotypes of Enterococcus faecium, 42 (76.4\%), 9 (16.4\%), and 4 strains $(7.3 \%)$ showed the vanA, vanB, and vanC phenotype, respectively. The 16 strains of Enterococcus gallinarum and 2 strains of Enterococcus casseliflavus showed the vanC phenotype and the 1 strain of Enterococcus avium had the vanB phenotype. The one strain of Enterococcus faecium propagated only in EV4 and was susceptible to both vancomycin and teicoplanin according to the antimicrobial susceptibility test using the VITEK 2 system. The vancomycin resistance phenotype gene was not detected by PCR. A total of 327 specimens were cultured in Enterococcosel broth supplemented with $6 \mu \mathrm{g} / \mathrm{mL}$ of vancomycin (EV6 broth), and 120 strains (36.7\%) were isolated. These 120 strains were subjected to vancomycin resistant genotyping by a multiplex real-time polymerase chain reaction and 51 strains (42.5\%) showed vanA; 5 strains (4.2\%) showed vanA and vanC; and 18 strains (15\%) showed vanC. Vancomycin resistance genotypes were not detected in the remaining 46 strains (38.3\%).
\end{abstract}

Key words: Antimicrobial susceptibility test, Enterococcosel broth, Multiplex real-time PCR, Vancomycin resistant enterococci, VITEK 2 system

This is an Open Access article distributed under the terms of the Creative Commons Attribution Non-Commercial License (http://creativecommons.org/licenses/by-nc/4.0) which permits unrestricted non-commercial use, distribution, and reproduction in any medium, provided the original work is properly cited.

Copyright () 2017 The Korean Society for Clinical Laboratory Science. All rights reserved.
Corresponding author: Young-Kwon Kim Department Biomedical Laboratory Science, College of Medical Sciences, Konyang University, 158 Gwanjeodong-ro, Seo-gu, Daejeon 35365, Korea

Tel: 82-42-660-6371

Fax: 82-42-543-6370

E-mail: ykkim3245@konyang.ac.kr

Co-Corresponding author: Sunghyun Kim Department of Clinical Laboratory Science, College of Health Sciences, Catholic University of Pusan, 57 Oryundae-ro, Geumjeong-gu, Busan 46252, Korea Tel: 84-51-510-0560 Fax: 82-51-510-0568 E-mail: shkim0423@cup.ac.kr

Received: November 3, 2017 Revised $1^{\text {st: }}$ November 15,2017 Revised $2^{\text {nd }}$ : November 21, 2017 Revised $3^{\text {rd. }}$ : November 28, 2017 Revised $4^{\text {th: }}$ : December 5, 2017 Accepted: December 6, 2017 


\section{서 론}

반코마이신 내성 장알균(vancomycin resistant enterococci, VRE)은 의료관련 감염의 대표적인 병원체로 1986년 유럽에서 처음 보고된 이래 현재에 이르기까지 30여년 동안 전 세계적으 로 분리 빈도가 증가하여 중요한 의료관련 감염균으로 자리 잡 고 있다[1]. VRE의 신속한 검출은 환자의 치료뿐 아니라 다른 환 자에게로의 전파를 예방할 수 있게 한다[2].

미국 National Nosocomial Infections Surveillance보고에 따르면 2003년 중환자실 환자에서 분리된 장알균 중 VRE 빈도 를 28.5\%로 보고하였다[3]. 국내에서도 1992년 처음으로 $\operatorname{vanA}$ 유전자를 가지는 Enterococcus durans 가 분리되었으며 국내 의료기관 내의 VRE 분리 비율이 1998년 이후 빠르게 증가 하고 있다[4,5]. 특히 중환자실의 경우 환자에서 분리된 장알균 중 반코마이신 내성 장알균 분리 비율이 낮았으나 2004년 29\%, 2006년에는 43\%, 최근 51\%로 급격하게 증가 하고 있다[6].

현재 국내 병원 시험실에서 실시하는 VRE 감시 배양법으로 는 대변 검체를 평판 배지 배양법인 반코마이신 $6 \mu \mathrm{g} / \mathrm{mL}$ 첨가된 Enterococcosel agar에 접종 후 검게 변한 집락을 혈액우무배 지에 계대배양 후 동정 시험과 항균제 감수성 시험을 실시하는데 보고하기까지 3 4일이 소요되어 정확하지만 시간이 오래 걸리 고 다중 중합효소 연쇄반응법(multiplex real-time PCR)을 이 용하여 VRE를 검출할 수 있는데, 이는 1 2일이 소요되어 빠르 지만 비용이 많이 든다는 단점이 있다[7].

이에 본 연구에서는 VRE 감시 배양으로 의뢰된 대변 검체 327 개를 대상으로 보다 신속하고 경제적인 VRE 감시배양을 실 시하고자 저자들이 고안한 반코마이신 첨가 배지(enterococcosel media with vancomycin, EV)와 VITEK 2를 이용하여 VRE 의 vancomycin 내성 유전자의 표현형과 유전형을 분석하여 국 내에서 분리된 VRE의 항균제 내성 양상과 관련 유전자와의 상 관성을 알아보고자 연구를 실시하였다.

\section{재료 및 방법}

\section{1. 연구대상}

2016년 1월부터 4월까지 전남 소재 C 종합병원에서 VRE 감 시 배양이 의뢰된 대변 검체 총 327 개를 대상으로 연구를 실시 하였다.

\section{2. 연구방법}

1) Enterococcosel 선택배지에서 VRE의 분리

Enterococcosel agar와 Enterococcosel broth (Beckton Dickinson, sparks, MD, USA)에 vancomycin (Sigma Chemical Company, St. Louis, $\mathrm{MO}$, USA)을 각각 $4 \mu \mathrm{g} / \mathrm{mL}$ (EV4), 6 $\mu \mathrm{g} / \mathrm{mL}$ (EV6), $12 \mu \mathrm{g} / \mathrm{mL}$ (EV12), $24 \mu \mathrm{g} / \mathrm{mL}$ (EV24)씩을 첨가 하여 대변 검체 총 327 개에 접종 한 후 $35^{\circ} \mathrm{C}, \mathrm{CO}_{2} 5 \sim 7 \%$ 배양 기에서 48시간 동안 배양하였다. Enterococcosel agar에서 검 게 변한 집락을 catalase시험 음성, 그람양성알균을 VRE로 잠 정 동정하였다.

\section{2) VITEK 2 시스템을 이용한 항균제 감수성 시험}

Enterococcosel agar에서 검게 변한 집락을 VITEK 2 system ID GP card (bioMe'rieux, France)를 이용하여 VITEK 2 System (bioMe'rieux, France)으로 동정하였다. E. gallinarum와 E. casseliflavus 및 E. faecium을 구별 동정하기 위해 methyl D-glucopyranoside (MGP) test를 실시하였다. Vancomycin 과 teicoplanin의 내성 여부를 알아보기 위해 VITEK-2 system AST 600 card (bioMe'rieux, France)를 사용하여 항균제 감수 성 시험을 하였다. 세균 부유액의 탁도를 McFarland tube 0.5 에 맞춘 후 Mueller-Hinton agar (MHA)에 접종하고, 배지의 중앙에 vancomycin $(30 \mu \mathrm{g}$ ) 항균제 디스크와 teicoplanin (30 $\mu \mathrm{g}$ ) 항균제 디스크를 $20 \mathrm{~mm}$ 간격으로 접종하였다. 접종한 배 지는 $37^{\circ} \mathrm{C}$ 항온기에 18 시간 배양 후 각 항균제에 대한 억제대를 확인하였다.

3) Anyplex VanR real-time PCR을 이용한VRE 유전자 검출 EV6 Enterococcosel broth (Beckton Dickinson, USA)에 접종 한 후 $35^{\circ} \mathrm{C}, \mathrm{CO}_{2} 5 \sim 7 \%$ 배양기에서 $16 \sim 24$ 시간 동안 배 양하였다. 검게 변한 액체배지 배양액 $50 \mu \mathrm{L}$ 를 DNA extraction

Table 1. Ct value interpretation of Anyplex VanR Real-Time PCR assay

\begin{tabular}{cccc}
\hline Analyte & Fluorophore & Ct value & Results \\
\hline vanA & FAM & $<40$ & Detected \\
& & $\mathrm{N} / \mathrm{A}$ & Undetected \\
vanB & Quasar 670 & $<40$ & Detected \\
& & $\mathrm{N} / \mathrm{A}$ & Undetected \\
vanC & Cal Red 610 & $<40$ & Detected \\
& & $\mathrm{N} / \mathrm{A}$ & Undetected \\
IC & Cal Gold 540 & $<40$ & Detected \\
& & $\mathrm{N} / \mathrm{A}$ & Undetected \\
\hline
\end{tabular}

Abbreviation: N/A, not amplified. 
solution $200 \mu \mathrm{L}$ 와 혼합한 뒤 heat block $100^{\circ} \mathrm{C}$ 에서 10 분간 비동화 시킨 후 $13,000 \mathrm{rpm}$ 에서 5 분간 원심 분리하여 $\mathrm{DNA}$ 를 추출하였다. $\operatorname{vanA}$ 와 $\operatorname{van} \mathrm{B}, \operatorname{van} \mathrm{C}$ 유전자에 특이적인 프라이머 쌍을 이용하는 Anyplex VanR real-time Detection kit (Seegene, Korea)를 사용하여 추출한 DNA $3 \mu \mathrm{L}$ 에 VanR 시험 시약에 포함된 5x VanR Oligo Mix (primer, template of internal control) $4 \mu \mathrm{L}$, 8-methoxypsoralen $3 \mu \mathrm{L}, 2 \mathrm{x}$ Detection Mix (DNA polymerase, buffer containing dNTPs) $10 \mu \mathrm{L}$ 를 혼합한 뒤 다중 실시간 중합 효소 연쇄반응시 험을 수행하였다. PCR 반응 방법은 CFX 96TM Real-time PCR System (Bio-Rad)을 이용하여 $95^{\circ} \mathrm{C}$ 에서 2 분간 반응 한 후 $95^{\circ} \mathrm{C} 30$ 초, $60^{\circ} \mathrm{C} 60$ 초 반응을 44 회 반복하였고, 형광물질 FAM, Cal Gold 540, Cal Red 610, Quasar 670을 이용하여 Anyplex VanR Real-Time PCR의 Ct value 판독기준에 따라 분석하였다(Table 1, Figure 1).

\section{결 과}

\section{Enterococcosel 배지에서 VRE의 분리}

대변 검체 327 개를 vancomycin을 첨가한 Enterococcosel $\mathrm{EV} 4, \mathrm{EV} 6, \mathrm{EV} 12, \mathrm{EV} 24$ 선택배지에 각각 배양한 결과 84주 (25.7\%)가 증식하였으며, EV4, EV6, EV12, EV24 배지 모두에 서 증식한 경우가 56건(17.1\%), EV4와 EV6 배지에서만 증식한 경우가 18 건(5.5\%), EV4 배지에서만 증식한 경우는 10 건 (3.1\%)이었다(Table 2).

\section{VITEK 2 시스템을 이용한 VRE 항균제 감수성 시험}

VITEK 2 시스템을 이용하여 총 327검체 중 74검체(22.6\%) 가 $6 \mu \mathrm{g} / \mathrm{mL}$ vancomycin이 첨가된 Enterococcosel (EVGagar)에 서 증식한 집락을 동정하였다. 이 중 55주(74.3\%)는 E. faecium, 16주(21.6\%)는 E. gallinarum, 2주(2.7\%)는 E. casseliflavus, 1주
(1.4\%)는 E. avium으로 동정되었다.

표현형 유전자 시험 결과, E. faecium 55 주 중 42주(76.4\%)가 $\operatorname{vanA}$ 표현형을 나타냈으며, 9주(16.4\%)는 vanB 표현형을 나타 냈고, 4주(7.3\%)는 vanC 표현형을 나타냈다. E. gallinarum 16 주와 E. casseliflavus 2주는 모두 vanC 표현형을 나타냈으며, $E$. avium 1주는 vanB 표현형을 나타냈다. EV4에서만 증식한 $E$. faecium 1 주는 VITEK 2 시스템을 이용한 항균제 감수성 시험 을 한 결과 vancomycin과 teicoplanin 모두 감수성이었고 PCR 로 확인한 결과 vancomycin 내성 표현형 유전자가 검출되지 않 았다(Table 3).

\section{Anyplex VanR real-time $P C R$ 을 이용한 Van 유전자의 검출}

327 개의 검체를 vancomycin $6 \mu \mathrm{g} / \mathrm{mL}$ (EV6)이 첨가된 Enterococcosel 액체배지(EV broth)에서 배양한 결과 120주 (36.7\%)가 분리되었으며, 120 주를 다중 중합 효소 연쇄반응으 로 vancomycin 내성 유전형 시험을 한 결과 51주(42.5\%)가 $\operatorname{vanA}$ 유전형을 나타냈으며, 5주(4.2\%)에서 $\operatorname{vanA}$ 와 $\operatorname{vanC}$ 유전 형을 나타냈고, 18주(15\%)에서 $\operatorname{vanC}$ 유전형을 나타냈으며, 나 머지 46주(38.3\%)에서는 vancomycin 내성 유전형 유전자가 검출되지 않았다(Table 4).

Table 2. Growth on different concentration EV agar from stool cultures 327 clinical isolates

\begin{tabular}{lccccc}
\hline \multicolumn{5}{c}{ Growth on different concentration of EV agar } \\
\hline \multicolumn{1}{c}{ EV agar } & EV4 & EV6 & EV12 & EV24 & $\begin{array}{c}\text { No. (\%) of } \\
\text { isolates }\end{array}$ \\
\hline All EV & 56 & 56 & 56 & 56 & $56(17.1)$ \\
EV4 and EV6 & 18 & 18 & - & - & $18(5.5)$ \\
Only EV4 & 10 & - & - & - & $10(3.1)$ \\
No growth on EV & 243 & 243 & 243 & 243 & $243(74.3)$ \\
Total & 327 & 317 & 299 & 299 & $327(100.0)$ \\
\hline
\end{tabular}

Abbreviation: EV. enterococcsel agar with vancomycin.

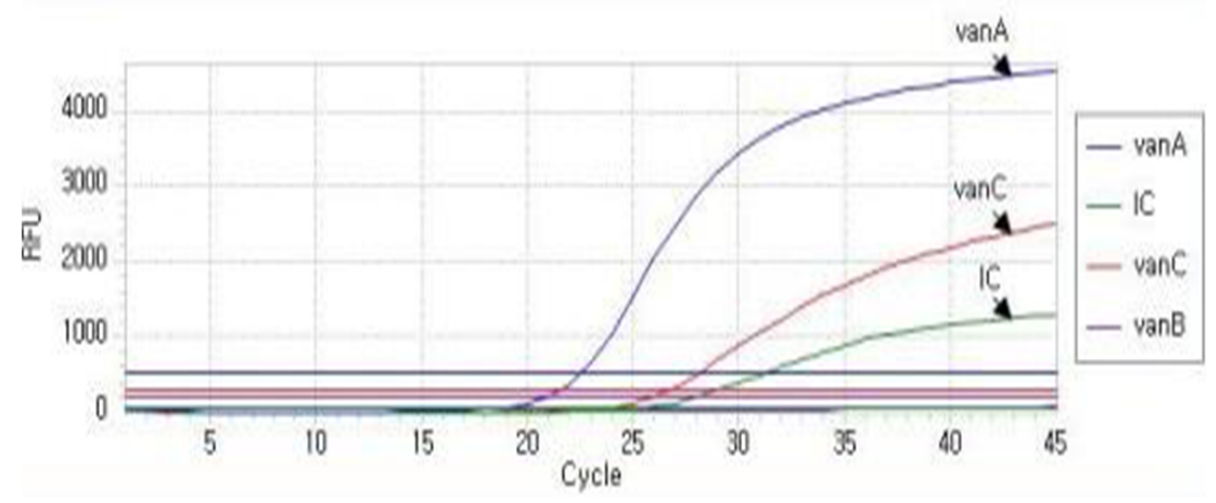

Figure 1. Amplification curve of Anyplex VanR Real-Time PCR assay. 
404 Min-Kyung Jeong, et al. Detection of Vancomycin-Resistant Enterococci and Related Genes Using VITEK 2 and Multiplex Real-time PCR

Table 3. Distribution of phenotypes and antimicrobial susceptibility test results of 74 VRE clinical isolates by Vitek 2 system

\begin{tabular}{|c|c|c|c|c|c|c|}
\hline \multirow{2}{*}{$\begin{array}{l}\text { Result by VITEK } 2 \text { ID } \\
\text { (No. of isolates) }\end{array}$} & \multirow{2}{*}{$\begin{array}{l}\text { No. of isolates } \\
(74)\end{array}$} & \multicolumn{2}{|c|}{ Vancomycin } & \multicolumn{2}{|c|}{ Teicoplanin } & \multirow[b]{2}{*}{ Phenotype } \\
\hline & & $\begin{array}{c}\mathrm{MIC} \\
(\mu \mathrm{g} / \mathrm{mL})\end{array}$ & $\begin{array}{l}\text { Disc inhibition } \\
(\mathrm{mm})\end{array}$ & $\begin{array}{c}\mathrm{MIC} \\
(\mu \mathrm{g} / \mathrm{mL})\end{array}$ & $\begin{array}{l}\text { Disc inhibition } \\
(\mathrm{mm})\end{array}$ & \\
\hline \multirow[t]{2}{*}{ E. faecium (42) } & 37 & 32 & $\leq 14$ & 32 & $\leq 10$ & $\operatorname{van} A$ \\
\hline & 5 & 32 & $\leq 14$ & 32 & $11 \sim 13$ & vanA \\
\hline \multirow[t]{3}{*}{ E. faecium (9) } & 5 & 32 & $\leq 14$ & 1 & $\geq 14$ & $\operatorname{van} B$ \\
\hline & 3 & 32 & $\leq 14$ & 1 & $11 \sim 13$ & $\operatorname{van} B$ \\
\hline & 1 & 32 & $\leq 14$ & 1 & $\leq 10$ & $\operatorname{van} B$ \\
\hline E. avium (1) & 1 & 32 & $\leq 14$ & 2 & $\leq 10$ & $\operatorname{van} B$ \\
\hline \multirow[t]{2}{*}{ E. faecium (4) } & 1 & 32 & $\leq 14$ & 4 & $11 \sim 13$ & $\operatorname{vanC}$ \\
\hline & 3 & 32 & $\leq 14$ & 16 & $\leq 10$ & $\operatorname{vanC}$ \\
\hline \multirow[t]{2}{*}{ E. gallinarum (16) } & 15 & 4 & $\geq 17$ & 0.5 & $\geq 14$ & $\operatorname{vanC}$ \\
\hline & 1 & 8 & $\geq 17$ & 0.5 & $\geq 14$ & $\operatorname{vanC}$ \\
\hline E. casseliflavus (2) & 2 & 4 & $\geq 17$ & 0.5 & $\geq 14$ & $\operatorname{vanC}$ \\
\hline
\end{tabular}

Table 4. Genotype distribution of 120 VRE clinical isolates from EV6 broth

\begin{tabular}{ccc}
\hline EV6 & $\begin{array}{c}\text { Genotypes result by } \\
\text { broth }\end{array}$ & No. (\%) of isolates \\
\hline Growth & vanA & 120 \\
& vanA, vanC & $51(42.5 \%)$ \\
& vanC & $18(15 \%)$ \\
& No detection & $46(38.3 \%)$ \\
No growth & No detection & $207(63 \%)$ \\
Total & $74(61.7 \%)$ & $327(100 \%)$ \\
\hline
\end{tabular}

\section{고 찰}

장알균(VRE)은 병독성이 높은 세균은 아니지만 중요한 의료 관련 감염균으로 국내 중환자실을 비롯하여 의료환경에 토착화 되어가고 있는 의료관련 감염균이다[8,9]. VRE의 유행과 전파 를 막기 위한 감염관리지침이 있으나 현실적으로 국내의 모든 병원에서 적용하기 어려울 뿐 아니라 시행하여도 확실히 근절 하기 힘든 의료관련 감염의 주요 다제내성균이다[9].

이전 연구에서는 임상 검체에서 분리한 장알균 279 주 중 26 주 에서 중합 효소 연쇄반응법과 $16 \mathrm{~S} \mathrm{rDNA}$ 의 염기순서분석법을사 용한 분자생물학적 동정 결과와 생화학적 동정 결과가 불일치함 을 보고하여[10] VRE의 정확하고 신속한 동정과 항균제 감수성 시험의 결과의 필요성을 강조하였다. 특히 VRE는 메티실린 내성 황색 포도알균(methicillin-resistant Staphylococcus aureus, $\mathrm{MRSA}$ )으로 내성 유전자를 전달할 수 있기 때문에, MRSA가 정착 화되어 있는 국내 병원에서 $\mathrm{VRE}$ 의 빠르고 정확하고 효율적인 동 정과 항균제 감수성시험의 결과는 매우 중요하다[11].

본 연구에서는 총 327 개의 검체를 전통적인 방법인 $\mathrm{EV} 6$ 평
판배지와 EV6 액체배지와 저자들이 새롭게 고안한 다양한 농도 의 vancomycin이 첨가된 EV agar를 이용하여 VITEK 2 시스 템에서의 동정과 $\mathrm{PCR}$ 을 통해 $\mathrm{VRE}$ 의 유전형과 표현형의 관계 를 비교하여 보았다. 본 실험에서는 VRE의 감시 배양을 위한 327 개의 검체를 $\mathrm{EV} 4, \mathrm{EV} 6, \mathrm{EV} 12, \mathrm{EV} 24$ 로 vancomycin 농도 를 다르게 하여 제조한 배지에서 vancomycin 농도에 따른 세 균 증식 여부를 관찰하고, 주로 병원에서 이용 되고 있는 6 $\mu \mathrm{g} / \mathrm{mL}$ vancomycin이 첨가된 배지의 정확성을 검증하기 위해 서 실시하였다. 이 중 84검체(25.7\%)가 vancomycin을 첨가한 Enterococcosel 선택배지에서 증식하였으며, EV4, EV6, $\mathrm{EV} 12 . \mathrm{EV} 24$ 선택배지 모두에서 증식한 경우가 56건(17.1\%), $\mathrm{EV} 4, \mathrm{EV} 6$ 선택배지에서만 증식한 경우가 18건(5.5\%), EV4 선 택배지에서만 증식한 경우는 10건(3.1\%)이었다. Vancomycin 농도에 따른 세균 증식에서는 기존의 vancomycin $6 \mu \mathrm{g} / \mathrm{mL}$ (EV6)배지가 VRE 검출에 효과적임을 확인 하였다. 또한 The multiplex PCR, Bruker MS와 VITEK MS의 결과를 비교한 결 과 E. faecalis, E. faecium, E. casseliflavus, E. gallinarum은 모두 일치 하였다. Fang H, Ohlsson AK 등의 보고에 의하면 VITEK 2 시스템과 비교한 결과는 E. spp.에서 $92.3 \%$ 의 일치율 을 나타낸다는 보고가 있다[12,13]. EV6 배지에 증식하여 혈액 우무배지에 계대배양할 때 서로 다른 두 집락이 증식하였는데 E. faecium이 우세하게 증식하였고 E. faecalis와 E. casseliflarus 는 소수의 집락으로 증식하여 우세하게 증식한 $E$. faecium만 VITEK 2 시스템으로 동정과 항균제 감수성시험을 실시하였으 며, 함께 증식한 E. faecalis와 E. casseliflanus 2주는 분리 할 수 없었다.

VRE는 주로 vanA, vanB, vanC형이 임상검체에서 검출되며 이 중 획득 내성의 주된 $\operatorname{vanA}$ 와 $\operatorname{vanB}$ 유전자형은 주로 $E$. faecium과 E. faecalis 가 대부분을 차지하고 있다[14-17]고 보 
고한 바 있으며, E. faecium과 E. faecalis는 임상에서 $90 \%$ 이상 분리되는 종이며, 나머지 E. casseliflarus, E. gallinarum, E. flavescens, E. avium은 5\% 이하로 드물게 분리된다는 보고도 있다[18]. VRE는 vanA, vanB, $\operatorname{vanC}$, $\operatorname{vanD}$, $\operatorname{vanE}$, vanG, $\operatorname{vanL}$ 7종류의 표현형이 있으며 해당 유전자에 의해 발현된다[19]. 본 연구에서도 $\mathrm{EV}$ 액체 배지에 배양 후 다중 $\mathrm{PCR}$ 법을 실시 한 결과 56주 중 55주가 vanA 유전형을 나타냈으며 E. faecium으로 동 정되었고, 1 주는 E. avium으로 동정되어 E. faecium이 대부분 임을 알 수 있었다. 본 연구에서는 최근 3 4년 동안 $\operatorname{vanB}$ 유전 형의 검출 결과가 없어서 추후 타 기관의 분리 빈도를 함께 역학 조사하여 지역적인 분포를 확인할 필요가 있을 것으로 생각된 다. 한편 glycopeptides계 항균제 내성 유전형과 표현형이 일 치하지 않는 VRE 균주도 검출되었다. 본 연구에서 분리된 VRE 균주들 중 $\operatorname{vanA}$ 의 유전형을 나타낸 51주의 항균제 감수성 시험 결과에 따른 표현형 분석 결과 $\operatorname{vanA}$ (40주), $\operatorname{vanB}$ (7주), $\operatorname{vanD}$ (4주)로 확인되었다. $\operatorname{vanA}$ 의 유전자형에 $\operatorname{vanB}$ 의 표현형을 가 진 VRE가 증가하는 추세를 보이고[13,20] 있으며, 국내에서는 $\operatorname{vanS}$ 유전자의 코돈에 IS1216V를 가짐으로써 teicoplanin에 대 한 내성 변이가 일어난 것으로 설명하는 보고도 있다[13]. 본 연 구에서도 $\operatorname{vanA}$ 의 유전자형에 $\operatorname{vanB}, \operatorname{vanD}$ 등 다른 표현형을 가 진 VRE가 꾸준히 분리되고 있어서 추후 이러한 균주들을 대상 으로 분자역학적인 연구가 필요할 것으로 생각된다.

\section{요 약}

이 연구에서 VITEK 2 시스템을 사용하여 $6 \mu \mathrm{g} / \mathrm{mL}$ vancomycin이 첨가된 Enterococcosel (EV6 agar에서 배양한 327 개의 검체 중 74 개의 분리균(22.6\%)으로 확인하였다. $E$. faecium은 55주(74.3\%), E. gallinarum 16주(21.6\%), $E$. casseliflavus 2주(2.7\%) 및 E. avium 1주(1.4\%)로 확인되었다. E. faecium의 55 가지 표현형 중 vanA가 42 주(76.4\%), vanB가 9주(16.4\%), $\operatorname{vanC}$ 표현형이 4주(7.3\%)로 나타났다. $E$. gallinarum 16주와 E. casseliflarus 2주 모두 vanC 표현형을 보였으며 E. avium 1주는 vanB 표현형을 나타내었다. EV4에서 만 증식된 E. faecium 1주는 VITEK2 시스템을 이용한 항균제 감수성 검사 결과 vancomycin과 teicoplanin에 모두 감수성이 었고 vancomycin 내성 표현형 유전자는 PCR에 의해 검출되지 않았다. 총 327 검체를 $6 \mu \mathrm{g} / \mathrm{mL}$ vancomycin (EV6 broth)을 첨가 한 Enterococoscosel broth에서 배양하여 120 균주 (36.7\%)가 분리되었다. 120 균주에서 다중 중합 효소 연쇄반응 에 의한 반코마이신 내성 유전형 실험을 실시한 결과, vanA가
51주(42.5\%), $\operatorname{vanA}$ 와 $\operatorname{vanC}$ 가 5 주(4.2\%), $\operatorname{vanC}$ 가 18 주(15\%), 나머지 46주(38.3\%)에서는 vancomycin 내성 유전형 유전자 는 검출되지 않았다.

\section{Acknowledgements: None}

Funding: None

Conflict of interest: None

\section{REFERENCES}

1. Leclercq R, Derlot E, Duval J, Courvalin P. Plasmid-mediated resistance to vancomycin and teicoplanin in Enterococcus faecium. N Engl J Med. 1988;319(3):157-161.

2. Palladino S, Kay ID, Flexman JP, Boehm I, Costa AM, Lambert EJ, et al. Rapid detection of vanA and vanB genes directly from clinical specimens and enrichment broths by real-time multiplex PCR assay. J Clin Microbiol. 2003;41(6):2483-2486.

3. National Nosocomial Infections Surveillance (NNIS) System Report, data summary from January 1992 through June 2004, issued October 2004. Am J Infect Control. 2004;32(8):470-485.

4. Kim JM, Song YG. Vancomycin-resistant enterococcal infections in Korea. Yonsei Med J. 1998;39(6):562-568.

5. Shin JW, Yong D, Kim MS, Chang KH, Lee K, Kim JM, et al. Sudden increase of vancomycin-resistant enterococcal infections in a Korean tertiary care hospital: possible consequences of increased use of oral vancomycin. J Infect Chemother. 2003;9(1):62-67.

6. Jeon MH, Park WB, Kim SR, Chun HK, Han SH et al. Korean Nosocomial Infections Surveillance System (KONIS) Report: Data Summary from July 2010 through June 2011. Korean J Nosocomial infect Control. 2012;17(1):28-39.

7. Cha CH, An HK, Kim JU. Detection of vancomycin-resistant enterococci using multiplex real-time PCR assay and melting curve analysis. Korean J Lab Med. 2010;30(2):138-146.

8. Lee WG. Resistance mechanism and epidemiology vancomycin resistance enterococci. Korean J Clin Microbiol. 2008;11(2): 71-77.

9. Yoon YK, Sim HS, Kim JY, Park DW, Sohn JW, Roh KH, Lee SE, Kim MJ. Epidemiology and control of an outbreak of vancomycin-resistant enterococci in the intensive care units. Yonsei Med J. 2009;50(5):637-643.

10. Angeletti S, Lorino G, Gherardi G, Battistoni F, De Cesaris M, Dicuonzo G. Routine molecular identification of enterococci by genespecific PCR and 16S ribosomal DNA sequencing. J Clin Microbiol. 2001;39(2):794-797.

11. Chang S, Sievert DM, Hageman JC, Boulton ML, Tenover FC, Downes FP, et al. Infection with vancomycin-resistant Staphylococcus aureus containing the vanA resistance gene. N Engl J Med. 2003;348(14):1342-1347.

12. Fang H, Ohlsson AK, Ullberg M, Ozenci V. Evaluation of species-specific PCR, Bruker MS, VITEK MS and the VITEK 2 system for the identification of clinical Enterococcusisolates. Eur J Clin Microbiol Infect Dis. 2012;31(11):3073-3077. 
13. Park IJ, Lee WG, Shin JH, Lee KW, Woo GJ. VanB phenotype-vanA genotype Enterococc us faecium with heterogeneous expression of teicoplanin resistance. J Clin Microbiol. 2008;46(9):3091-3093.

14. Hong KS, Kang ES, Lee MA. Investigation of prevalence of vancomycin-resistant entericocci and genotypes of glycopeptide resistance using polymerase chain reaction. Korean J Clin Pathol. 1998;18(3):372-378.

15. Lee SY, Park JH, Park HS, Lee MA, Kang ES, Hong KS. Comparison of antimicrobial susceptibility testing methods to detect glycopeptide resistance in enterococci: E-test, Vitek, disk diffusion and agar dilution method. Korean J Clin Pathol. 2000;20(3):301-307.

16. Park JH, Lee SY, Lee MA, Chung WS. Investigation of risk factors for vancomycin-resist ant enterococci (VRE) infection and colonization. Korean J Clin Pathol. 2000;20(3):306-313.

17. Kwon OG, Uh Y, Jang IH, Lee MK, Yoon KJ, Kim HY. Trend of isolation and genotypes of vancomycin-resistant enterococci isolated from tertiary care hospital in wonju area. Korean J Clin Pathol. 2000;20(5):486-493.

18. Papaparaskevas J, Tassios PT, Kalapothaki V, Avlami A, Legakis NJ, Vatopoulos AC. Epidemiology of multiresistant Enterococcus avium isolates in a greek tertiary care hospital. Int J Antimicrob Agents. 2002;20(6):432-437.

19. Boyd DA, Willey BM, Fawcett D, Gillani N, Mulvey MR. Molecular characterization of Enterococcus faecalis N06-0364 with low-level vancomycin resistance harboring a novel DAla-D-Ser gene cluster, vanL. Antimicrob Agents Chemother. 2008;52(7):2667-2672.

20. Song JH, Ko KS, Oh WS, Park S, Heo ST, Kwon KT, et al. High frequency of vancomycin-resistant Enterococcus faecium isolates with VanB phenotype and vanA genotype in korean hospitals. Diaqn Microbiol Infect Dis. 2006;56(4):401-406. 